\title{
A avaliação da aprendizagem a distância: um estudo em representações sociais'
}

\author{
Evaluation of distance learning: a study in social representations
}

Vânia Maria de Oliveira Vieira[ ${ }^{[a]}$, Manoella Stein Nascimento Silva ${ }^{[b]}$, Marilene Ribeiro Resende ${ }^{[c]}$

\footnotetext{
${ }^{[a]}$ Universidade de Uberaba (Uniube), Uberaba, MG - Brasil, e-mail:vaniacamila@uol.com.br ${ }^{[b]}$ Universidade de Uberaba (Uniube), Uberaba, MG - Brasil, e-mail: manoellastein@hotmail. com

${ }^{[c]}$ Universidade de Uberaba (Uniube), Uberaba, MG - Brasil, e-mail: marilene.resende@uol. com.br
}

Recebido: 30/11/2011 Received: $11 / 30 / 2011$

Aprovado: 04/10/2012 Approved: 10/04/2012

\section{Resumo}

Este estudo consiste em um relato de pesquisa sobre a avaliação da aprendizagem na modalidade a distância. Optou-se pelo suporte teórico-metodológico da Teoria das representações sociais explicitada por Moscovici (1978, 2003), Jodelet (2011) Abric (2001) e Sá (2002). Tem como objetivo identificar as representações sociais que os alunos de pedagogia a distância de uma universidade mineira estão construindo sobre a avaliação da aprendizagem. Os procedimentos de coleta de dados incluíram a aplicação de um questionário, com questões abertas e outras formuladas de acordo com a escala Likert; a técnica de associação livre de palavras, tratadas pelo software Evoc, que busca identificar nas representações sociais os elementos centrais e periféricos; e a realização de grupos focais. Participaram da pesquisa 212 alunos concluintes do curso de pedagogia a distância dos polos Triângulo (Araxá, Uberaba, Uberlândia); Espírito Santo (Cariacica, Colatina) e Regional Triângulo Mineiro (São Gotardo). De acordo com as análises realizadas, foi possível verificar que o projeto pedagógico do curso prevê uma avaliação processual e formativa. Os dados demonstram também que os alunos estão construindo diferentes representações sobre a avaliação a distância. Possivelmente, essas representações estão ancoradas em sentimento que denota ser a avaliação: "uma atividade de aprendizagem e conhecimento" (53\%); "adequada que permite a realização de um curso a distância, porém exige dedicação e persistência" (20\%); "complexa, rigorosa, tradicional, classificatória e que não mede conhecimentos" (27\%).

Palavras-chave: Educação a distância. Representações sociais. Avaliação da aprendizagem. Formação de professores.

\section{Abstract}

This study consists of a research report on the evaluation of a distance learning course. We chose theoretical and methodological supports of Social Representation Theory explained by Moscovici (1978, 2003), Jodelet (2011), Abric (2001) and Sá (2002). Its objective is to identify the social representations that students of a distance learning course of University of Minas Gerais in Brazil

1 Esta pesquisa se insere no âmbito de uma investigação maior coordenada pelo Centro Internacional de Estudos em representações sociais e Subjetividade - educação - CIERS-Ed. Conta com o apoio financeiro da Fundação de Amparo à Pesquisa de Minas Gerais - FAPEMIG.

Psicol. Argum. 2014 jul./set., 32(78), 137-147 


\begin{abstract}
are constructing on their evaluation of learning. The procedures for data collection included the use of a questionnaire with open questions and others formulated according to Likert scale; the technique of free association of words by Evoc software, which tries to identify social representations of central and peripheral elements, and the organization of focus groups. 212 graduating students of the pedagogy distance learning course participated in the research of the School of Education of the Minas Triangle (Araxá, Uberaba, Uberlândia), Espírito Santo (Cariacica, Colac) and Minas Triangle region (São Gotardo). According to the analysis performed, we found that the pedagogical project of the course provides a procedural and formative assessment. The data also show that students are constructing different representations of distance learning. Possibly these representations are anchored in the idea that the evaluation is "an activity of learning and knowledge" (53\%), "an adequate activity for a distance course, but it requires dedication and persistence" (20\%); "complex, rigorous, traditional, classificatory, but it does not measure knowledge" (27\%).
\end{abstract}

Keywords: Distance education. Social representations. Assessment of learning. Professor formation.

\section{Introdução}

Um dos maiores desafios que a educação enfrenta atualmente é o de conseguir que todos os alunos tenham uma aprendizagem satisfatória, que lhes permita uma integração à sociedade e a vivência em um novo mundo, com rápidas e complexas mudanças. Entretanto, as escolas e universidades continuam com dificuldades para efetivar suas práticas de ensino e avaliação.

Fernandes (2009, p. 19) acredita que a forma como a aprendizagem e a avaliação têm sido oferecidas nas escolas tem dificultado para os alunos o pleno desenvolvimento das "competências indispensáveis para prosseguirem livremente sua vida escolar ou profissional".

Sabe-se que, atualmente, a avaliação é uma das dimensões mais complexas do processo educativo, não só na modalidade a distância, como também na presencial. Vieira (2006, p. 15) mostra que "a avaliação existe com o objetivo de se conhecer o que o aluno já aprendeu e o que ele ainda não aprendeu, para que se providenciem os meios de ele aprender o necessário para a continuidade dos estudos". A avaliação considerada a partir dessa perspectiva torna-se uma grande aliada, tanto do aluno como do professor. Luckesi (2011, p. 263) também afirma que a "avaliação da aprendizagem não é, e nem pode continuar sendo a prática pedagógica tirana que ameaça e submete a todos com um poder discricionário". Aponta ainda que a avaliação deve ser um recurso pedagógico do professor para auxiliar o aluno na busca da sua autoconstrução.

Desse modo, essa pesquisa sobre as representações sociais que os alunos do curso de pedagogia na EAD estão construindo sobre a avaliação da aprendizagem é mais uma tentativa de trazer contribuições para esse campo importante da educação. Embora muito se tenha discutido e pesquisado sobre esse tema, percebe-se a existência de lacunas nessa área, com certa escassez de estudos e reflexões.

O conceito de "representações sociais" surgiu em 1961, na França, com a obra de Moscovici, La Psychanalyse, son image, son public, por meio do resgate do conceito de representação coletiva de Durkheim, mas com algumas diferenças. Para Durkheim, as representações são coletivas (1898), permanentes, tradicionais, amplamente distribuídas, ligadas à cultura e transmitidas lentamente por gerações. 0 fenômeno social não depende da natureza pessoal dos indivíduos. Para Moscovici, as representações são sociais (1961), dinâmicas, típicas, de culturas modernas, espalham-se rapidamente por toda a população e possuem curto período de vida. 0 indivíduo tem papel atuante e particular na construção das representações sociais.

A teoria de Moscovici procura entender a dinâmica das relações do indivíduo com o meio social, concentrando o interesse em como se dá essa relação. Pode-se dizer então que as representações sociais são formadas no contexto da vida diária, através das palavras, dos gestos, nas comunicações sociais, onde se estabelece vínculos e construções 
de realidade. É uma forma de conhecimento específico que tem como papel a formação de comportamentos e a comunicação entre os sujeitos. Através delas é que se consegue comunicar e, por assim dizer, agir com os outros (Jodelet, 2001). Segundo Moscovici (1978, p. 181):

Por representações sociais queremos indicar um conjunto de conceitos, explicações e afirmações interindividuais. São equivalentes, em nossa sociedade, aos mitos e sistemas de crenças das sociedades tradicionais; poder-se-ia dizer que são a versão contemporânea do senso comum.

Como assinalado, as representações sociais se referem ao modo de pensar e interpretar. Isso possibilita que os sujeitos consigam dar sentido a sua vida. Por meio delas, pode-se apreender como os sujeitos se relacionam para formar a realidade.

Segundo Moscovici (1984), citado por Sá (1996), há dois processos geradores de representações sociais: a ancoragem e a objetivação.

0 primeiro é um processo que torna algo desconhecido ou estranho em algo familiar ou habitual e o iguala a uma categoria que é própria ao indivíduo. Ancorar é também classificar e denominar um novo objeto; aquilo que não é denominado ou não classificado torna-se estranho e desconhecido. Através deste processo, uma representação pode se transformar em um organizador das relações.

Trindade, Santos e Almeida (2011, p. 110), referindo-se ao conceito de ancoragem proposto por Moscovici, apontam que esse processo:

permite ao indivíduo integrar o objeto da representação em um sistema de valores que lhe é próprio, denominando e classificando-o em função dos laços que esse objeto mantém com sua inserção social. Assim o novo objeto é ancorado quando ele passa a fazer parte de um sistema de categorias já existente, mediante alguns ajustes.

Ancorar, nas palavras de Moscovici (2003, p. 61), é, portanto, "classificar e dar nome a alguma coisa". Para esse autor, "coisas que não são classificadas e que não possuem nome são estranhas, não existentes e ao mesmo tempo ameaçadoras".

O segundo processo, a objetivação, tem a função de duplicar um sentido por uma figura, dar materialidade a um objeto abstrato, naturalizá-lo - o sujeito materializa um significado. É um processo em que há corporificação de um conhecimento pelo indivíduo. Tem a função de reproduzir um conceito (abstrato) em uma imagem (concreta). Na objetivação, a imagem vai se transformar em um objeto. "Trata-se, enfim, de transformar o que é abstrato, complexo ou novo em imagem concreta e significativa, apoiando-se em concepções que nos são familiares" (Trindade; Santos \& Almeida, 2011, p. 110)

Abric, em 1976, em sua tese de doutorado, propõe a teoria do núcleo central ou abordagem estrutural da teoria das representações sociais. Essa teoria constitui-se em uma abordagem complementar, uma subteoria à grande teoria de Moscovici.

Abric (2001, p. 163) sustenta a hipótese de que toda representação se organiza em torno de um núcleo central e um periférico. "O núcleo central é o elemento fundamental da representação, pois é ele quem determina ao mesmo tempo sua significação e sua organização".

O núcleo central é o elemento mais estável da representação social, o mais resistente à mudança - quando modificado, toda a representação muda, tendo, então, duas representações distintas. Ele é coerente, rígido e pouco sensível ao contexto imediato. Está ligado à memória coletiva e à história do grupo. Além de ser consensual e definir a homogeneidade do grupo (Abric, 1994 citado por Sá, 1996).

O sistema periférico, ao contrário do núcleo central, é flexível e suporta as contradições. Protege o núcleo central das modificações, sendo a parte mais flexível das representações sociais e permite a elaboração da representação relacionada às histórias individuais dos sujeitos.

Segundo Flament (2001, p. 178), "a periferia das representações serve de para-choque entre uma realidade que a questiona e o núcleo central que não deve mudar facilmente". 0 autor afirma ainda que o sistema periférico é importante para as representações, uma vez que possui um caráter maleável, flexível e evolutivo; permite a adaptação à realidade e integra as experiências e histórias individuais, já que suporta a heterogeneidade e as contradições. (Flament, 2001).

Na medida em que forem identificadas as representações sociais dos alunos, será possível desvelar como esse grupo compreende a avaliação da aprendizagem na modalidade a distância. Assim, poder-se-á refletir, discutir e verificar, conforme aponta

Psicol. Argum. 2014 jul./set., 32(78), 137-147 
Luckesi (2011), se a avaliação tem cumprido o seu papel. Para esse autor, uma avaliação - entendida como um dos componentes do ato pedagógico - realiza o que lhe compete quando auxilia o desenvolvimento do aluno. Caso isso não ocorra, a avaliação não fará "o seu papel de subsidiária da ação, já que a sua função é retratar a qualidade da realidade para intervenções adequadas, tendo em vista a construção dos melhores resultados possíveis" (Luckesi, 2011, p. 73).

A teoria das representações sociais tem como objetivo explicar os fenômenos do homem a partir de uma perspectiva coletiva, sem perder de vista a individualidade dos sujeitos. Sua finalidade é tornar familiar algo não familiar, classificar, categorizar, nomear novos acontecimentos e ideias. No cotidiano, as pessoas conversam, pensam e analisam os mais diferentes temas, e, assim, elaboram representações. Essas representações passam a influenciar suas relações e comportamentos sociais. É por meio da identificação das representações que os problemas podem ser superados e integrados no nosso mundo mental e físico. 0 que era abstrato torna-se concreto. Com a elaboração das representações sociais, transforma-se o novo, o desconhecido, em algo familiar. Enquanto que o não familiar intriga e gera desconforto, o familiar torna-se conhecido e gera a confirmação das crenças. Assim, "o ato de reapresentação é um meio de transformar o que nos perturba, o que ameaça nosso universo, do exterior para o interior, do longínquo para o próximo" (Moscovici, 2003, p.56).

É o que propomos neste estudo: desvendar o desconhecido sobre a avaliação a distância, possibilitando, assim, emergir conteúdos não nomeados, ameaçadores, em algo familiar. A partir do momento em que se conhece o que aflige, torna-se possível pensar, refletir e propor possíveis soluções.

\section{Métodos}

Embora tenham sido utilizados alguns dados quantitativos, esta pesquisa caracteriza-se por uma abordagem qualitativa, entendida por Flick (2009, p. 37) como sendo a que se destina "à análise de casos concretos em suas peculiaridades locais e temporais, partindo das expressões e atividades das pessoas em seus contextos locais". Neste estudo, os dados quantitativos foram utilizados com o intuito de auxiliar as análises de cunho qualitativo.

Optou-se pelo suporte teórico-metodológico da teoria das representações sociais explicitada, principalmente, por Moscovici $(1978,2003)$ e Jodelet (2011), Abric (2001) e Sá (2002).

Os procedimentos de coleta de dados incluíram a aplicação de um questionário, contendo questões abertas e outras formuladas de acordo com a escala Likert; a técnica de associação livre de palavras, tratadas pelo software Evoc, que busca identificar nas representações sociais os elementos centrais e periféricos; e a realização de grupos focais. Este último, entendido por Kalampalikis (2010) como um método de coleta de dados, singular e único, com o objetivo de complementar e suplementar informações obtidas de outro instrumento, constitui um espaço de comunicação que permite engajar e analisar tensões na construção das representações sociais. A análise dos conteúdos teve também como base os pressupostos de Bardin (1979).

O questionário foi aplicado a 212 alunos concluintes do curso de pedagogia a distância, de diversos polos - Triângulo (Araxá, Uberaba, Uberlândia); Espírito Santo (Cariacica, Colatina) e Regional Triângulo Mineiro (São Gotardo). A aplicação ocorreu durante os encontros presenciais nos respectivos polos. Todos os alunos presentes no dia da aplicação foram convidados a participar.

O questionário, com questões abertas e fechadas, referia-se à identificação do perfil dos sujeitos e das representações sociais construídas por eles sobre a avaliação da aprendizagem. O perfil identificou aspectos sociais, econômicos e culturais dos alunos, e as representações foram identificadas por meio de questões específicas.

Foram analisados, ainda, documentos relativos à EAD e ao projeto pedagógico do curso de pedagogia da instituição pesquisada, com o intuito de se conhecer o locus da pesquisa e suas possíveis influências na construção das representações dos alunos.

Os resultados e as análises seguintes referem-se ao contexto da pesquisa, ao perfil dos alunos, e às representações construídas por eles sobre a avaliação da aprendizagem na EAD. Para identificação das representações, foram analisados, principalmente, as questões do questionário, os dados fornecidos pelo EVOC e os conteúdos das entrevistas de grupo focal sem desconsiderar o estudo do contexto e o perfil dos sujeitos. 


\section{Resultados e discussão}

\section{A educação a distância: locus da pesquisa}

A educação a distância, de certa forma, atende a uma parcela significativa de pessoas que, por razões diversas, não conseguiram chegar aos meios universitários.

No Brasil, essa prática teve início na década de 1930 com a criação do Serviço de Radiodifusão Educativa, do Ministério da Educação. As aulas eram transmitidas pelas rádios e acompanhadas por material impresso.

0 respaldo legal para o ensino a distância surge, no Brasil, com a Lei de Diretrizes e Bases da Educação Nacional - Lei 9.394, de 20 de dezembro de 1996 - que estabelece, em seu artigo 80, a possibilidade de uso orgânico de EAD em todos os níveis e modalidades de ensino. Esse artigo foi regulamentado posteriormente pelos decretos 2.494 e 2.561, de 1998, mas ambos revogados pelo decreto 5.622, em vigência desde sua publicação em 20 de dezembro de 2005 (MEC, 2007).

Morais (2010) alerta que a EAD não deve se reduzir à ideia apenas de ensino por computadores e redes virtuais, mas, sim, de forma mais ampla - que compreende a organização das atividades de ensino e aprendizagem. É preciso considerar também que o ensino a distância depende de fatores diferentes do ensino na educação presencial, como a autodisciplina e a capacidade de autoinstrução do estudante, a qualidade dos materiais, as formas de cooperação e a divisão de trabalho, planejamento e outros. É importante, ainda, que haja os polos presenciais, onde os alunos possam ter acesso a uma biblioteca, salas de estudo e reuniões (Morais, 2010).

A instituição pesquisada - locus deste estudo foi credenciada no ano de 2005 para ministrar cursos superiores a distância, pela Portaria do MEC no 1.871, de 2 de junho 2005, embora diversas atividades ligadas à capacitação do seu quadro docente e administrativo para atuar nessa modalidade já estivessem ocorrendo desde 2000.

A proposta pedagógica do curso de pedagogia apresenta a organização do curso, a maneira como é construída a aprendizagem, o processo de acompanhamento, o material didático e o método utilizado para a avaliação.

0 curso é organizado em três anos e meio, com duas etapas em cada ano. Durante cada etapa, estão previstos momentos de encontros presenciais, que são divididos em quatro oficinas de apoio à aprendizagem, com carga horária de oito horas cada uma, e dois seminários de integração, com carga horária de dezesseis horas cada um.

Os seminários de integração constituem-se como um momento de encontro entre os alunos e os preceptores e/ou professores especialistas. Esses encontros acontecem uma vez a cada trimestre, totalizando uma carga horária de 32 horas por etapa/ semestre.

Já as oficinas de apoio à aprendizagem são coordenadas pelos preceptores, e têm por objetivo a ampliação de habilidades, entre elas a do trabalho em equipe, a elaboração de projetos integrados e também a socialização de experiências vivenciadas nos estudos individuais.

Nesse curso há também estudos individuas a distância e estudos independentes, com o objetivo de auxiliar a construção da aprendizagem. Para a realização dos estudos individuais, o aluno tem como referência o "guia do aluno" e os quinze volumes de roteiros que contêm os textos básicos, exercícios, orientações sobre a prática pedagógica e as leituras complementares. A construção da aprendizagem conta ainda com o estágio supervisionado, de 400 horas, que se desenvolve "por meio das atividades da prática educativa, no âmbito da gestão, da Educação Infantil e do ensino nos anos iniciais do Ensino Fundamental" (Uniube, 2007, p. 30).

0 contato entre o preceptor e os alunos ocorre, presencialmente, durante os Seminários de Integração e nas oficinas de apoio à aprendizagem, conforme cronograma previsto para cada etapa. Mas, sempre que necessário, os alunos podem buscar orientações fora dos momentos destinados aos encontros presenciais obrigatórios, desde que previamente agendados. Pode haver também contatos complementares por telefone, fax ou pelo ambiente virtual Teleduc.

Como método avaliativo, o projeto prevê que este deve se realizar ao longo do curso, de forma processual e formativa, com o objetivo de "permitir ao preceptor e ao aluno reconhecer os conhecimentos construídos em cada etapa do processo de ensino-aprendizagem" (Uniube, 2007, p. 31).

As avaliações devem ser realizadas com instrumentos variados para que seja possível avaliar o aluno de forma global. As provas escritas/avaliações individuais são realizadas em 8 horas presenciais a

Psicol. Argum. 2014 jul./set., 32(78), 137-147 
cada etapa. A nota do aluno é representada numericamente em uma escala de 0 a 100 pontos, conforme as normas internas da instituição - 100 pontos para a avaliação processual, realizada no decorrer da etapa, e 200 pontos para duas avaliações presenciais, com duração de 4 horas cada uma. 0 processo de avaliação inclui momentos de autoavaliação dos alunos, preceptores e equipe multidisciplinar (Uniube, 2007).

\section{Perfil dos alunos}

Os dados relacionados ao perfil dos sujeitos permitem identificar algumas características importantes para a compreensão das representações sociais construídas pelos licenciandos sobre a avaliação da aprendizagem.

Dos 212 sujeitos participantes, 206 são do sexo feminino, o que denota uma característica desse curso no país. Em relação à idade, observou-se que a faixa etária está bem distribuída, $25 \%$ possuiu de 25 a 40 anos, e os menores percentuais estão na faixa de "até 24 anos" (5\%) e "acima de 50 anos" (9\%). Esses dados indicam que o ensino a distância atrai pessoas com idade superior à dos alunos brasileiros, que normalmente cursam uma graduação até os 24 anos.

Grande parte dos estudantes (45\%) declarou ser da cor parda, e outra parcela, também relevante (41\%), da cor branca, seguida de $6 \%$ da cor negra, $4 \%$ da cor amarela, e ainda $4 \%$ se declararam indígenas.

Em relação ao estado civil, $61 \%$ do total de alunos são casados, o que compreende a grande maioria deles, e $24 \%$ são solteiros. Uma parcela desses alunos (5\%) ainda se declarou como separados, e outros em regime de união estável (7\%). Em conformidade com esses dados, $75 \%$ dos entrevistados moram com o esposo(a) e/ou filhos(as), 14\% com os pais, e apenas $9 \%$ moram sozinhos.

Quanto à escolaridade do pai e da mãe, $58 \%$ e $53 \%$, respectivamente, não concluíram o ensino fundamental. No que concerne à ocupação, entre uma variedade grande de profissões apontadas, destacam-se, por incidência maior, os aposentados, falecidos e lavradores, e das mães, donas de casa, aposentadas e domésticas. Esses dados referentes à escolaridade e ocupação dos pais mostram que os alunos advêm de famílias de baixo nível de escolaridade e de profissões pouco rentáveis, o que confirma a origem social modesta, como registrado também por Gatti em relação aos alunos das licenciaturas no Brasil (2009, p. 164).

Foi verificado, ainda, que, em relação à escolaridade, apenas $24 \%$ dos sujeitos da pesquisa apresentam outro curso superior.

Em relação à inserção dos alunos no mercado de trabalho, a maioria, 202 (96\%), declarou estar empregada. Dos alunos que estão empregados, $36 \%$ declararam que, apesar de ter seu próprio salário, ainda dependem do dinheiro da família, contra 33\% que não dependem do dinheiro da família, e $27 \%$ que sustentam outras pessoas.

Quanto ao tempo de trabalho, 6\% dos estudantes, que declararam estar empregados, trabalham há menos de 2 anos; $16 \%$, de 2 a 5 anos; $17 \%$, de 6 a 10 anos; $19 \%$, de 11 a 15 anos; $19 \%$, de 16 a 20 anos, e 23\% trabalham há mais de 21 anos. Um número considerável, 117 alunos (55\%), declararam que trabalham na área da educação, sendo que $48 \%$ trabalham com educação infantil (creche e pré-escola); $51 \%$ no ensino fundamental e $1 \%$ no ensino médio.

Em relação à renda familiar, incluindo o salário do educando, quando este também trabalha, os dados indicam que grande parte possui uma renda mensal total que varia entre $R \$ 416,00$ a $R \$$ 1.245,00. Esses dados também são corroborados por Gatti (2009, p. 164): 39,2\% com renda familiar de até três salários-mínimos e "escassa frequência de sujeitos nas faixas mais elevadas de renda".

Quanto às razões que os levaram a optar por um curso de licenciatura, grande parte dos alunos (46\%) visa ao mercado de trabalho e $25 \%$ por gostar do curso. 0 restante, $19 \%$, por desejar ser professor; 7\%, por querer ser alguém na vida, e apenas $2 \%$ por terem sido obrigados por outras pessoas.

No que diz respeito aos recursos procurados pelos alunos para seu aperfeiçoamento, 85\% declararam que têm o hábito de ler outros livros além dos que são indicados pelo curso, e apenas 1\% dos alunos declara não usar computador para realizar as tarefas escolares. Dessa quantidade de alunos que utiliza o computador, a maioria deles (86\%) utiliza-o principalmente em casa.

Sintetizando, pode-se afirmar que os sujeitos são, na maioria, do sexo feminino; pertencem a famílias de baixa escolaridade e nível socioeconômico modesto; já atuam como docente no ensino fundamental - o que deve ser considerado ao apontar 
as representações sociais que estão sendo construídas, pois trazem estreita relação com a forma como percebem e concebem a avaliação da aprendizagem.

\section{Representações sociais e núcleo central}

Solicitou-se aos sujeitos que escrevessem 03 (três) palavras que lhes viessem à mente ao ler a frase "Avaliação da aprendizagem em curso a distância" e depois assinalassem a mais importante, justificando em seguida sua resposta.

Esta associação livre resultou em uma lista de 636 palavras que foram processadas no programa Evoc e organizadas em quatro quadrantes de acordo com a frequência média das palavras evocadas (10) e a média das ordens das evocações $(1,9)$.

Pode-se observar que a maioria citou três palavras diferentes, isto é, as palavras pouco se repetem, o que pode significar pouca representação sobre esse conceito.

No estudo do fenômeno das representações sociais, a ordem das palavras evocadas também deve ser considerada, e a partir da análise dessa ordem foi possível a formação de grupos de representações, considerando também a frequência e a ordem da emissão de cada uma. A figura seguinte explicita melhor a evocação das palavras (Anexo 1).

A partir da análise desses dados, foi possível apontar que as palavras "difícil" e "dificuldade" (28), "conhecimento" (26) e "aprendizagem" (18), com maior número de incidências, podem evidenciar as representações sociais dos sujeitos acerca da avaliação da aprendizagem. Isto é, para esse grupo de alunos do curso de pedagogia, a avaliação no curso a distância significa uma atividade difícil, que demanda responsabilidade, mas que traz aprendizagem e conhecimento.

Provavelmente, essas palavras revelam-se como nucleares em relação ao conteúdo representacional ligado à prática da avaliação dos alunos do curso de pedagogia na modalidade a distância, por terem sido as palavras com maior frequência.

Nesse sentido, as palavras que compõem esse grupo podem representar o que pensam os respondentes quando se lembram da avaliação da aprendizagem no curso a distância. Nos dizeres de Sá (2002, p. 118), esse conjunto de palavras é facilmente interpretado: "ele engloba as cognições mais suscetíveis de constituir o núcleo central da representação, na medida em que são aquelas mais frequentes e prontamente evocadas pelos sujeitos".

A realização do grupo focal trouxe contribuições importantes para as análises realizadas. Pudemos confirmar e/ou tirar dúvidas sobre alguns dados do questionário.

Em relação à palavra "difícil" - uma das mais evocadas e consideradas como elemento do núcleo central -, o grupo focal permitiu perceber que, para esses alunos, a avaliação presencial, ou seja, a prova escrita é estressante e aplicada de modo tradicional. Algumas falas ilustram o estabelecimento de um clima desfavorável e perturbador à realização da avaliação: "Mas a presencial, é que causa esse medo, [...] você não pode olhar para o outro, você não pode olhar pra frente [...]". "É totalmente tradicional, senta um atrás do outro, uns três ou quatro fiscais na sala, a gente não pode virar pro lado". "Te mandam só uma apostila, é um compromisso, é responsabilidade, [...]".

No segundo grupo aparecem as palavras "responsabilidade (18)", "comprometimento/compromisso" (17) e "extensa/grande" (15). A frequência dessas palavras mostra que elas se aproximam muito do núcleo central, ou seja, tem representatividade significativa. Esse grupo parece entender a prática da avaliação como sendo uma atividade extensa, grande e que envolve comprometimento e compromisso na sua realização. As palavras "compromisso" e "responsabilidade", com frequência 17 , reforçam a compreensão de avaliação associada à de aprendizagem - avaliação exige compromisso e responsabilidade, ao mesmo tempo em que dá oportunidade do desenvolvimento dessas atitudes. "Os enunciados são muito grandes. Às vezes você tem a folha inteira pra responder uma resposta curta". "Aquele enunciado às vezes te embaralha a cabeça, você não sabe qual resposta vai responder, qual é a certa, pelo tamanho do enunciado".

As palavras "objetiva" (14), "complexa/complicada" (12) e "estudar" (12) formam o terceiro grupo. Os sujeitos que o compõem demonstram compreender a avaliação na modalidade a distância como uma atividade que requer objetividade, é complexa e complicada, por isso exige estudo. "Então, nas palavras lá, eu coloquei 'complexa', porque eu vejo dessa forma. Tem muita coisa, são muitas questões".

No quarto grupo aparecem as palavras "reflexão" (11), "prática" (11) e "oportunidade" (10). Para esses sujeitos, avaliar tem o mesmo significado que

Psicol. Argum. 2014 jul./set., 32(78), 137-147 
estudar e refletir sobre o que aprendeu. Essas palavras constituem elementos importantes nas representações, mas não se afirmam como núcleo central. Para esses sujeitos, a prática da avaliação é uma oportunidade de poder acompanhar e atualizar os conhecimentos. "[...] Foi um meio que me proporcionou oportunidade para a conclusão de meu nível superior e realização enquanto profissional". "A avaliação nos leva a refletir sobre tudo o que estudamos durante um determinado período [...] com ela posso refletir sobre o meu processo de ensino e aprendizagem [...] através da avaliação refletimos sobre os conteúdos estudados durante o período, o que é muito bom, pois temos assim uma autoavaliação antes e depois da avaliação".

Como já foi dito anteriormente, foi solicitado que o respondente, após a evocação das palavras associadas à avaliação, apontasse uma palavra considerada mais importante e, em seguida, justificasse sua escolha. A intenção dessa atividade foi estabelecer uma análise entre os elementos mais evocados em relação à avaliação, e aqueles considerados os mais importantes.

Realizou-se a categorização das justificativas com o suporte teórico de Bardin (2007) e com o enfoque da teoria das representações sociais.

Dos 212 sujeitos respondentes do questionário, 33 não responderam essa questão. Portanto, foram registradas 179 palavras consideradas as mais importantes com suas respectivas justificativas.

Essas palavras e justificativas foram agrupadas em três categorias:

1. Uma atividade de aprendizagem e conhecimento - 95 sujeitos $-53 \%$;

2. Uma avaliação adequada que permite a realização de um curso a distância, porém exige dedicação e persistência - 35 sujeitos - 20\%;

3. Uma avaliação complexa, rigorosa, tradicional, classificatória e que não mede conhecimentos 49 sujeitos $-27 \%$.

Os textos dos 95, ou seja, 53\% dos sujeitos que compõem a primeira categoria apresentam palavras e expressões que denotam ser a avaliação uma atividade de aprendizagem e conhecimento. Palavras como "aprendizagem", "conhecimento", "estudo", "necessária", "reflexão" e outras são apontadas como reveladoras do que seja a avaliação para esse grupo. As justificativas seguintes caracterizam essa categoria. "Eu aprendi muito com o curso e ainda vou aprender, é através de leituras que eu faço uma boa prova escrita [...] Estuda-se mais do que aqueles que frequentam uma faculdade presencial, estou em constante aprendizagem, em busca de informações. Avalia o aluno em processo contínuo e em um todo, oportunizando o crescimento do mesmo".

Vale ressaltar que esta categoria, em relação às outras, contém o maior número de sujeitos, corresponde a $53 \%$ do total. Isto, em termos de representações, pode indicar que a maioria dos alunos está construindo uma representação social acerca da avaliação como sendo uma atividade positiva, que contribui para a aprendizagem e construção de conhecimentos.

Quanto ao grupo focal, também é perceptível, nas falas dos participantes, a ênfase em questões relacionadas a essa categoria: "Quando eu vejo que errei, que a nota foi baixa, eu procuro estudar mais. Então, acho que pra mim é um incentivo". "O curso é muito bom; quem quer estudar mesmo, com comprometimento, quem quer aprender consegue, de uma forma dinâmica, de uma forma que você já sai daqui pronto pra encarar uma sala de aula com certeza, e um concurso público também".

0 segundo grupo é composto de 36 alunos, representando $20 \%$ dos entrevistados. Palavras e expressões ditas por esse grupo parecem revelar que aprovam a avaliação como é proposta, pois oportunizada oportunidades para a realização do curso. Mas acham também que para isso precisam ter dedicação, esforço e disciplina nos estudos.

Entre as palavras mais citadas por esse grupo, encontramos: "oportunidade", "disponibilidade", "dedicação", "persistência", "perseverança", "disciplina". E expressões tais como: "Para aprender de maneira dedicada e reforçada, o curso a distância e sua avaliação dá brecha para o estudo mais flexível nos horários. Quando a pessoa escolhe um curso a distância tem que ter disciplina para estudar e organizar o seu modo de vida".

No grupo focal, os participantes reforçam a ideia de que a avaliação é adequada, e quando há dedicação e persistência nos estudos, permite a realização de um curso a distância. "Quando eu optei pelo curso a distância foi pela disponibilidade do horário". "Acho que é importante que a avaliação aconteça, mesmo que fique todo mundo muito tenso e nervoso [...] Eu sei que existem as outras notas e outros tipos de avaliação, mas quando chega essa hora [prova] 
eu me sinto testada, me sinto assim, me sinto bem quando vejo a nota. Quando eu vejo que errei, que a nota foi baixa, eu procuro estudar mais. Então, acho que pra mim é um incentivo".

"Rigorosa", "tradicional", "difícil”, "classificatória", "desnecessária" e "não mede conhecimentos", são algumas das palavras e expressões citadas pelos alunos da terceira categoria, para exprimir o sentimento em relação à avaliação a que são submetidos. Compõem essa classe 49 sujeitos, ou seja, 27\% dos entrevistados. "Acredito que não somos crianças, mas nas avaliações somos tratadas como tal; Os profissionais que aplicam a avaliação às vezes causam transtornos, medo, o que torna complicada a sua realização; A Universidade é tradicional quanto à avaliação, nunca ouve e aceita a opinião dos alunos, agindo injustamente; 0 processo avaliativo visando à formação do aluno, pelo redimensionamento da prática pedagógica fundamentada numa perspectiva inovadora, a instituição possui uma proposta contrária, teoria e prática curriculares são divergentes; As provas estão muito difíceis; Sinto-me insegura, porque os roteiristas não conhecem a minha realidade; A avaliação em si, sabemos que não dá resultado correto, sabemos da necessidade do estudo e de aprendizagem, assim como da diferença entre as pessoas; É sujeita à cola, ao nervosismo, por isso não envolve nosso conhecimento e envolvimento verdadeiro com o curso".

Nesses textos encontramos indícios de que, para esse grupo, a avaliação tem sido compreendida como uma atividade negativa, que não contribui para o processo de aprendizagem dos alunos. Parece ser a avaliação fragmentada do contexto de aprendizagem e com intenção de ser punitiva, ameaçadora, classificatória e segregadora.

Para os integrantes do grupo focal, a aplicação das "provas" sempre ocorre em um clima tenso; citam diversos fatores que contribuem para isso: o horário de realização (à tarde), após as aulas no período da manhã; salas de aula muito cheias; a presença de fiscais que não são os professores/preceptores que acompanham o processo de aprendizagem; a falta de uma aula para revisão com o propósito de tirar dúvidas e trocar experiências. "Eu acho que é isso também que deixa a gente um pouco assim [tensa], porque a gente não tem antes uma aula, um aulão. Eu gostaria que tivesse essa revisão. Esse aulão seria uma troca de experiência. Eu penso que quem tem que vir dar a prova é aquela pessoa que me acompanhou no meu processo, é o meu professor [alunas de Colatina]". Ora, o que percebemos é que esses fatores evidenciam a realização da prova como um momento pontual, fragmentado do processo de ensino e aprendizagem.

Outra questão, também muito citada pelos participantes do grupo focal, que reforça as ideias dessa categoria - prova tradicional, rigorosa, classificatória - é o fato de não terem um feedback após as avaliações. Afirmam que não têm acesso à prova após a correção, e isso os impede de verificar os erros e acertos, ou seja, as aprendizagens não construídas. "Esse retorno falta, aí passa para o próximo módulo [...] eu consegui a média? Consegui! Mas vão ficar dúvidas naquelas questões na quais eu não avancei. Não é que eu não alcancei a média, eu alcancei a média. Mas, teve questões que eu errei. O que eu errei?".

Quanto às questões formuladas de acordo com a escala Likert, podem ser destacadas as seguintes análises em relação à avaliação da aprendizagem:

- Os sujeitos acreditam que a avaliação é capaz de provocar reflexões, além de favorecer a autoavaliação, segundo 82\% do grupo total;

- A maioria (85\%) considera que a avaliação é formativa e processual, mas, em contrapartida, $53 \%$ do grupo disseram que a avaliação é classificatória, seletiva e excludente.

- Quanto à complexidade das questões, 90\% dos alunos acreditam que não têm coerência com o conteúdo apresentado nos roteiros, além de que $40 \%$ relatam que elas são muito subjetivas;

- No que se refere à articulação entre teoria e prática, a maioria dos alunos acredita que a avaliação é capaz de promover essa integração entre os saberes, sendo que apenas 7\% discordaram dessa afirmação;

- Em relação ao processo de aprendizagem, 81\% dos alunos relatam que a avaliação ajuda a compreender como esse processo está sendo percorrido;

- E, no que diz respeito ao ritual em que é realizada a avaliação presencial, ele é percebido como algo cansativo e constrangedor para os alunos.

\section{Considerações finais}

As análises aqui realizadas apontam alguns elementos que provavelmente constituem as

Psicol. Argum. 2014 jul./set., 32(78), 137-147 
representações sociais dos licenciandos sobre a avaliação da aprendizagem na EAD.

Os elementos destacados no núcleo central remetem a uma avaliação "complexa e difícil" que exige estudo e revela a "qualidade" do curso. Isto implica que seja esse, provavelmente, o núcleo central da representação social desses sujeitos. Portanto, algo ligado à memória coletiva, estável, rígido e resistente a mudanças.

Por outro lado, o sistema periférico revela as contradições presentes quando se discute a avaliação. Reconhece-se que ela é formativa, necessária, está associada à aprendizagem, ao conhecimento, à necessidade de reflexão, como, também, que é classificatória, rigorosa, cansativa, causa ansiedade, medo e insegurança.

Com relação às três categorias referentes às justificativas das palavras evocadas, aparece com maior porcentagem de participantes a que demonstra ser "a avaliação uma atividade que auxilia a aprendizagem e o conhecimento do aluno", com 55\%. Em seguida, tem-se a categoria, "uma avaliação complexa, rigorosa, tradicional, classificatória e que não mede conhecimentos", com 27\%. Esse grupo contrapõe as representações construídas pelo primeiro e contraria a perspectiva de avaliação apresentada na proposta pedagógica do curso. Para eles, a avaliação tem ocorrido de forma tradicional - além de ser muito difícil, tem causado medo e insegurança. Por último, aparece a categoria "uma avaliação adequada que permite o ensino a distância, porém exige dedicação e persistência", com $20 \%$ de participação dos respondentes. Esse grupo, em conformidade com o primeiro, parece estar construindo também uma representação positiva sobre a avaliação da aprendizagem, principalmente por ela permitir, entre outras atividades, a possibilidade de esses alunos cursarem uma graduação na modalidade a distância.

Em termos de porcentagem, pode-se dizer que a maioria, ou seja, 73\% dos respondentes estão construindo uma representação social positiva em relação à avaliação da aprendizagem. Em contrapartida, outro grupo, com $27 \%$, tem percebido a avaliação como uma atividade punitiva, segregadora e que não possibilita a aprendizagem ou os conhecimentos do aluno.

0 perfil dos alunos, predominantemente mulheres adultas, casadas, empregadas, com renda familiar que se concentra nas faixas de um até dois salários-mínimos, advindas de famílias de baixo nível de escolaridade e de profissões pouco rentáveis, confirma a origem social e cultural modesta. Essas características, próprias de alunos nessa modalidade, contribuem para a compreensão do surgimento de termos como "esforço", "compromisso", "responsabilidade", "dedicação", e "autonomia". Esses foram os aspectos mais evidenciados, na perspectiva dos alunos, quando descrevem sua aprendizagem, constatados na pesquisa de Resende e Vieira (2011).

A análise dos dados demonstra também, em relação à avaliação, um alto consenso entre os sujeitos quanto à vontade de aprender, ter disciplina, dedicação e esforço. Percebem a avaliação nos cursos a distância como facilitadora da construção da aprendizagem e um conhecimento que se adquire com responsabilidade. Também essa constatação tem suscitado várias dúvidas quanto aos motivos e às dimensões em que essa satisfação ocorre. Seria uma satisfação apenas em um nível afetivo no sentido de conquistar algo que parecia impossível? Seria uma satisfação decorrente de pouca exigência do aluno no que se refere a sua formação, considerando as suas origens sociais, condições de vida e profissionais? Pode ser uma satisfação realmente originária do fato de que as avaliações estão sendo realizadas de forma processual, reflexiva e formativa?

São muitas as questões para serem refletidas e discutidas a partir das representações colocadas neste estudo - o não familiar tornou-se agora familiar; o que antes era estranho, ameaçador, agora está ancorado, nomeado, categorizado e classificado. Resta então oportunizar discussões e propor ações que viabilizem a busca de uma avaliação que cumpra o seu papel, como apontado por Luckesi - a de auxiliar o desenvolvimento do aluno.

\section{Referências}

Abric, J. C. (2001). O estudo experimental das representações sociais. In D. Jodelet (Org.). As representações sociais. (pp. 155-171). Rio de Janeiro: Eduerj.

Bardin, L. (1977). Análise de Conteúdo. Lisboa: Edições 70.

Ministério da Educação (2007). Secretaria de Educação a distância. Referenciais de qualidade para Educação Superior a Distância. Recuperado em 30 nov. 2009, de http://www.planalto.gov.br/ccivil_03/_Ato20042006/2005/Decreto/D5622.htm. 
Fernandes, D. (2009). Avaliar para aprender: fundamentos, práticas e políticas. São Paulo: Editora Unesp.

Flament, C. (2001). Estrutura e dinâmica das representações sociais. In D. Jodelet (Org.). As representações sociais.( pp. 173-86). Rio de Janeiro: Eduerj.

Flick, U. (2009). Introdução à pesquisa qualitativa. 3. ed. Porto Alegre: Artmed.

França, G. (2009). Os ambientes de aprendizagem na época da hipermídia e da educação a distância. Perspectiva, Ciência e Informação, 14(1).

Franco, M. L. P. B. Análise de Conteúdo. Brasília: Plano Editora, 2003.

Gatti, B. A. (2009) (Cood.), \& Barreto, E. S. S. Professores do Brasil: impasses e desafios. Brasília: Unesco.

Jodelet, D. (2001). Representações sociais: um domínio em expansão. In D. Jodelet (Org.). As representações sociais. Rio de Janeiro: Eduerj.

Kalampalikis, N. (2010) Seminário de Estudos Avançados: des Représentations Sociales: ancrages, terrains, tensions. Conferência. USP-SP.

Luckesi, S. C. (2011). Avaliação da aprendizagem: componente do ato pedagógico. São Paulo: Cortez Editora.

Moscovici, S. (1978) A representação social da Psicanálise. Rio de Janeiro: Zahar.
Moscovici, S. (2003). Representações Sociais: investigações em psicologia social. Petrópolis, RJ: Vozes.

Neves, J. L. (1996). Pesquisa Qualitativa: características, usos e possibilidades. Caderno de Pesquisa em Administração, 1(3).

Sá, C. P. (2002). Núcleo Central das representações sociais. 2. ed. Petrópolis-RJ: Vozes.

Trindade, Z. A., Santos, M. F. S, \& Almeida, A. M. O. (2011). Ancoragem: notas sobre consensos e dissensos. In:A. M. O. Almeida, M. F. S. Santos, \& Z. A. Trindade (Orgs.). Teoria das representações sociais: 50 anos. (pp. 101122). Brasília: TechonoPolitik.

Uniube. Portal da Instituição. Recuperado em 08 abr. 2010, de http://www.uniube.br/copese/ead/

Uniube. Projeto Político Pedagógico do Curso de Pedagogia na Modalidade a Distância. Recuperado em 08 abr. 2010, de http://www.uniube.br/copese/ ead/

Vieira, V. M. O. Representações sociais e avaliação educacional: o que revela o portfólio. 2006. Doutorado em Educação (Psicologia da Educação), Pontifícia Universidade Católica de São Paulo.

Psicol. Argum. 2014 jul./set., 32(78), 137-147 